\title{
Long-Term Follow-Up Results of Anterior Cervical Inter-Body Fusion with Stand-Alone Cages
}

Woong-Beom Kim, M.D., Seung-Jae Hyun, M.D., Ph.D., Hoyong Choi, M.D., Ki-Jeong Kim, M.D., Tae-Ahn Jahng, M.D., Hyun-Jib Kim, M.D. Department of Neurosurgery, Spine Center, Seoul National University Bundang Hospital, Seoul National University College of Medicine, Seongnam, Korea

Objective : The purpose of this study was to evaluate long-term follow-up radiologic/clinical outcomes of patients who underwent anterior cervical discectomy and inter-body fusion (ACDF) with stand-alone cages (SAC) in a single academic institution.

Methods : Total 99 patients who underwent ACDF with SAC between February 2004 and December 2012 were evaluated retrospectively. A total of 131 segments were enrolled in this study. Basic demographic information, radiographic [segmental subsidence rate, fusion rate, C2-7 global angle, and segmental angle changes)/clinical outcomes (by Odom's criteria and visual analog score (VAS)] and complications were evaluated to determine the long-term outcomes.

Results : The majority were males ( 55 vs. 44) with average age of 53.2. Mean follow-up period was 62.9 months. The segmental subsidence rate was $53.4 \%$ and fusion rate was $73.3 \%$. In the subsidence group, anterior intervertebral height (AlH) had more tendency of subsiding than middle or posterior intervertebral height $(p=0.01)$. The segmental angle led kyphotic change related to the subsidence of the AlH. Adjacent segmental disease was occurred in $18(18.2 \%)$ patients. Total $6(6 \%)$ reoperations were performed at the index level. There was no statistical significance between clinical and radiological outcomes. But, overall long-term clinical outcome by Odom's criteria was unsatisfactory (64.64\%). The neck and arm VAS score were increased by over time.

Conclusion : Long-term outcomes of ACDF with SAC group were acceptable but not satisfactory. For optimal decision making, more additional comparative long-term outcome data is needed between ACDF with SAC and ACDF with plating.

Key Words : Anterior cervical discectomy and fusion · Stand-alone cage $\cdot$ Subsidence $\cdot$ Long-term outcomes · Intervertebral height $\cdot$ Odom's criteria.

\section{INTRODUCTION}

Anterior cervical discectomy and inter-body fusion (ACDF) with stand-alone cages (SAC) has been regarded as an acceptable treatment option for symptomatic cervical degenerative disease. Not a few previous reports have described that ACDF with SAC is satisfactory in terms of radiographic and clinical results ${ }^{16-18)}$. However, several investigators reported that the cage subsidence and kyphotic angular change after the procedure ${ }^{13,1,424)}$. Nevertheless, the subsidence rate and kyphotic segmental change was not significantly associated with clinical outcome in a shortterm follow-up series, ${ }^{8,11)}$.

About superior surgical outcomes among ACDF with SAC, $A C D F$ with anterior plating or artificial disc are still controversial. We previously reported that ACDF with plating had better radiologic outcome than stand-alone cage group ${ }^{13)}$. In that study, we suggested that anterior plating may play a key role in the support of anterior inter-body height ${ }^{2}$. However, not a few studies have mentioned ACDF with SAC is a clinically/radiologically satisfactory procedure ${ }^{11,16-18)}$. However, there has been few long-term follow-up data about the ACDF with SAC. Furthermore, most of recent published reports included two-year or much lower follow-up period ${ }^{11}$.

The purpose of this study was to evaluate the long-term followup radiographic and clinical outcomes of patients having ACDF with SAC in a single academic institution.

\section{MATERIALS AND METHODS}

This study was approved by the institutional review board. After IRB approval, we retrospectively reviewed the records of all patients treated with single-, two-, and three-level ACDF with SAC

• Received : March 25, 2016 • Revised : March 25, 2016 • Accepted : May 6, 2016

- Address for reprints : Seung-Jae Hyun, M.D., Ph.D.

Department of Neurosurgery, Spine Center, Seoul National University Bundang Hospital, Seoul National University College of Medicine, 82 Gumi-ro 173beon-gil, Seongnam 07061, Korea

Tel : +82-31-787-7169, Fax : +82-31-787-4097, E-mail : hyunsj@snu.ac.kr

- This is an Open Access article distributed under the terms of the Creative Commons Attribution Non-Commercial License (http://creativecommons.org/licenses/by-nc/3.0) which permits unrestricted non-commercial use, distribution, and reproduction in any medium, provided the original work is properly cited. 
from February 2004 to December 2012. Patients having cervical radiculopathy or myelopathy caused by cervical degenerative disc disease and spondylosis who failed conservative management were included. The exclusion criteria included systemic infection, malignancy, C7/T1 involved disease, inability to measure the C2-7 angle because of a short neck, no clinical/radiographic follow-up data and less than 24 months follow-up period. Total six spine surgeons performed the operations in those periods. Demographic information, radiological studies and clinical presentation were reviewed for each case before and after surgery.

\section{Surgical technique}

Smith and Robinson method was used for the approach to the anterior cervical spine ${ }^{19)}$. Intervertebral disc, posterior longitudinal ligament and osteophyte were resected with endplate preparation. In cases with radiculopathy, uncoforaminotomy was utilized for the neural foraminal decompression. For determining the appropriate cage size, a trial cage was used. Polyether-ether-ketone (PEEK) or carbon fiber cage filled with allograft or autograft cancellous bone obtained from the anterior iliac crest were used for ACDF. The cage was located 1-2 mm depth from the anterior margin of the vertebral body. Neck collars were applied to the patients for 4-12 weeks after ACDF.

\section{Assessment of radiologic and clinical outcomes}

For radiologic outcomes, the cage subsidence, fusion rate, C2-7 global angle, and segmental angle were evaluated by the plain radiographs. Adjacent segmental disease was investigated by follow-up magnetic resonance (MR) imaging and medical chart reviewing.

Subsidence was defined as a decrease of the total intervertebral height (TIH) between the two adjacent vertebral bodies by comparing the lateral cervical radiographs. We compared the first postoperative, one-month, one-year, two-year standing radiographs and the ultimate follow-up radiographs ${ }^{21)}$. The TIH was measured by three portion; anterior, middle and posterior points of the upper end plate of the cranial vertebral body and the lower end plate of the caudal vertebral bodies. More than $3 \mathrm{~mm}$ decrease at any of the three points was considered to represent significant subsidence (Fig. 1) $)^{6,7)}$.

Fusion was defined as less than $2 \mathrm{~mm}$ change between the tips of the spinous processes of the treated level by the comparing the flexion-extension lateral radiographs or definite bony bridge of the index level on a lateral plain radiograph or computed tomographic (CT) scan ${ }^{4}$. The global cervical angle between the $\mathrm{C} 2$ and $\mathrm{C} 7$ vertebrae was measured. The segmental angle was defined as the angle between the upper end plate of the upper vertebral body and the lower end plate of the lower vertebral body. Negative values of the segmental angle and the global cervical angle mean cervical lordosis ${ }^{13,14)}$. For clinical outcomes, Odom's criteria and visual analog scales (VAS) were used ${ }^{25)}$. We categorized Odom's criteria as Excellent (1), Good (2), Fair (3), and Poor (4). Then we reviewed all the medical records of the patients at the ultimate visit and the Odom's criteria were filled out. Neck and arm VAS were checked pre- and postoperatively (annual fashion), and the ultimate follow-up period of the index surgery.
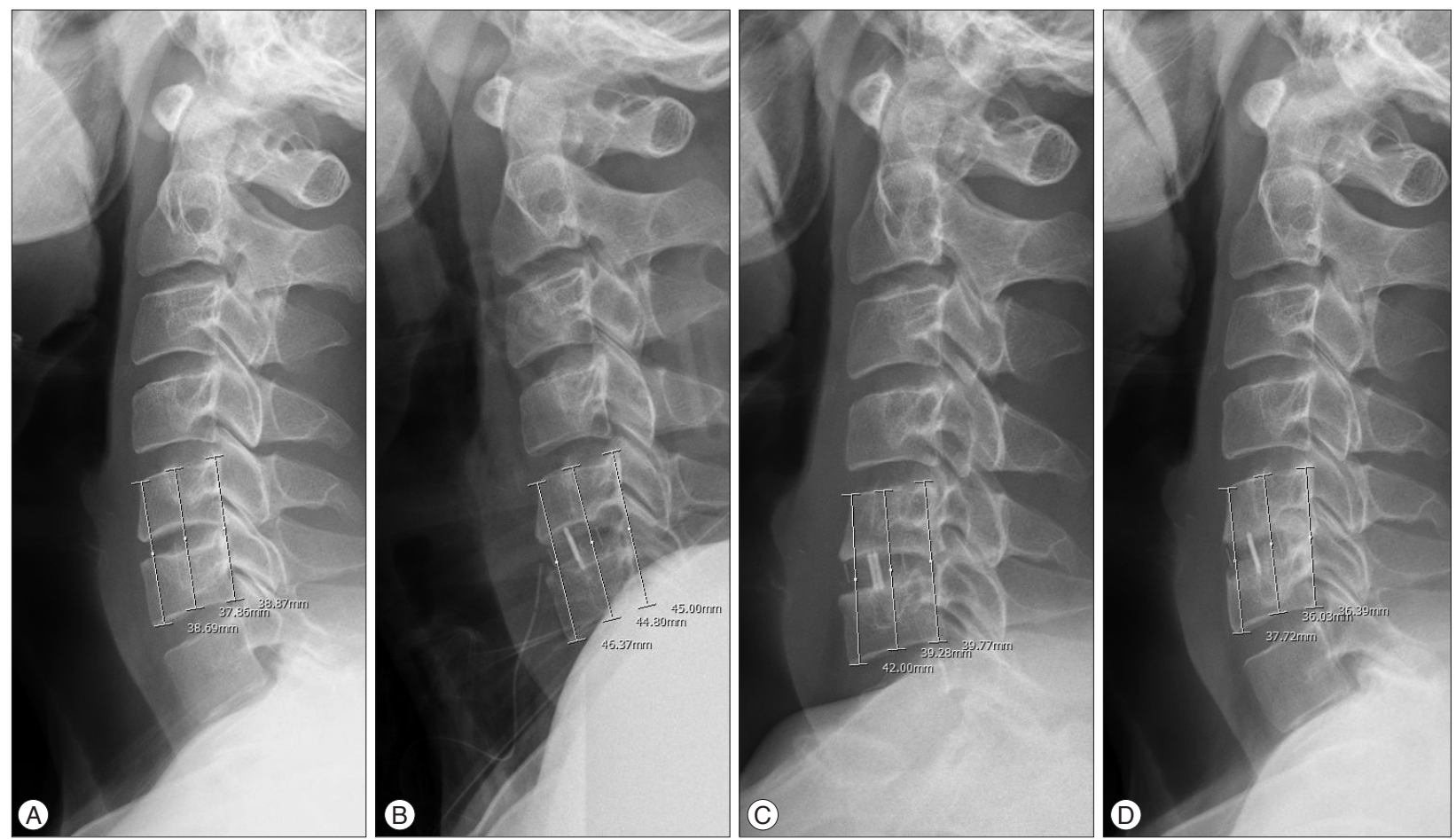

Fig. 1. A : Preoperative cervical spine lateral radiograph. B, C, and D : Postoperative cervical spine lateral radiograph show subsidence (B : Immediate postoperative standing radiograph, $\mathrm{C}: 1$ month postoperative standing radiograph, $\mathrm{D}:$ Ultimate follow-up period radiograph). 


\section{Statistical analysis}

Pearson's chi-square test was used for the baseline differences in nominal variables analysis. Student's t-test and the Mann-Whitney $U$ test for parametric and nonparametric continuous variables were used for the analysis of baseline characteristics between the two groups, respectively. A repeated measure analysis of variance (RM-ANOVA) of one between and one within mixed design was performed for radiologic and clinical outcomes between the subsidence (S-) and non-subsidence (NS-) groups, also fused (F-) and non-fused (NF-) groups. All data were analyzed using SPSS version 22 for Windows (SPSS Inc., Chicago, IL, USA).

\section{RESULTS}

A total 367 patients underwent ACDF with SAC from February 2004 to December 2012. Finally, a total of 99 consecutive patients were included in this study. The majority were males (55 vs. 44 ) with average age of 53.2 (range, 23-81) years. The number of ACDF with SAC at one-, two- and three-level was 68 , 29, 2 patients, respectively. For each individual segment, a total
131 segments were enrolled in this study. Surgical level was as followed : 6 segments at C3/4, 25 segments at C4/5, 61 segments at $\mathrm{C} 5 / 6$, and 39 segments at C6/7. Mean follow-up period was 62.9 (range, 28-135) months (Table 1).

Subsidence occurred in 70 (53.4\%) segments and 57 (57.6\%) patients at the ultimate follow-up period. Subsidence at anterior intervertebral height $(\mathrm{AIH})$ was significant than middle intervertebral height $(\mathrm{MIH})$ and posterior intervertebral height (PIH). Average $5.40 \mathrm{~mm}$ of subsidence of $\mathrm{AIH}$ was occurred at the ultimate follow-up and the subsidence was progressed over time $(p<0.001)$ in the S-group. However, the AIH change in the NSgroup was only $1.33 \mathrm{~mm}$ and less progressed over time than the S-group $(p<0.001)$. The MIH changes were $4.83 \mathrm{~mm}$ and progressed over time in the S-group, $1.07 \mathrm{~mm}$ and less progressed over time in the NS-group at the ultimate follow-up period. The $\mathrm{PIH}$ subsidence was occurred less than $\mathrm{AIH}$ [incidence of $64.3 \%$ (45 over 70 S-group)] with an average $3.93 \mathrm{~mm}$ change $(p<0.001)$. Comparing the TIH change in the S-group between 1 month postoperative and the ultimate follow-up data, $2.26 \mathrm{~mm}$ at AIH, 1.54 $\mathrm{mm}$ at $\mathrm{MIH}$, and $1.1 \mathrm{~mm}$ at PIH were observed (Table 2, Fig. 2).

Table 1. Patient demographics with or without subsidence

\begin{tabular}{|c|c|c|c|}
\hline Baseline characteristics & Subsidence (S-group) & No subsidence (NS-group) & $p$-value \\
\hline Number & 70 & 61 & \\
\hline Age & $53.6 \pm 11.2$ & $52.7 \pm 8.7$ & 0.673 \\
\hline Gender (male : female) & $36: 21$ & $19: 23$ & 0.058 \\
\hline BMD & $-1.25 \pm 1.5$ & $-1.2 \pm 0.8$ & 0.91 \\
\hline Level & & & 0.28 \\
\hline $\mathrm{C} 3 / 4$ & $2(2.9 \%)$ & $4(6.6 \%)$ & \\
\hline $\mathrm{C} 4 / 5$ & $14(20 \%)$ & $11(18 \%)$ & \\
\hline $\mathrm{C} 5 / 6$ & $31(44.3 \%)$ & $30(49.2 \%)$ & \\
\hline $\mathrm{C} 6 / 7$ & $23(32.9 \%)$ & $16(26.2 \%)$ & \\
\hline Segmental angle, preoperative & $0.92 \pm 4.99$ & $0.78 \pm 3.67$ & 0.97 \\
\hline $\mathrm{TIH}$, preoperative & & & 0.50 \\
\hline Anterior & $34.07 \pm 3.20$ & $34.45 \pm 3.10$ & \\
\hline Middle & $32.86 \pm 3.14$ & $33.26 \pm 2.85$ & \\
\hline Posterior & $34.47 \pm 2.95$ & $35.06 \pm 2.76$ & \\
\hline Global cervical angle, preoperative & $-12.05 \pm 10.5$ & $-11.16 \pm 9.5$ & 0.67 \\
\hline
\end{tabular}

$\mathrm{BMD}$ : bone mineral density, $\mathrm{TIH}$ : total intervertebral height
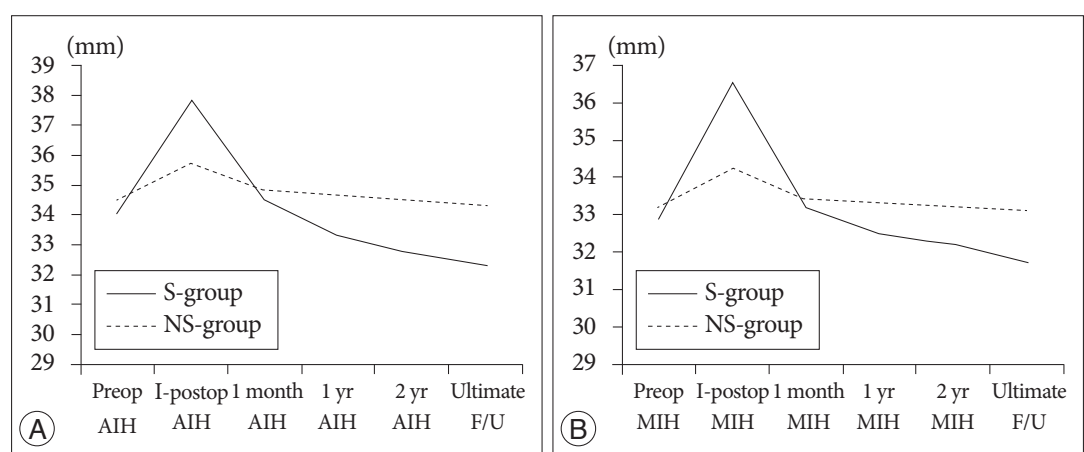

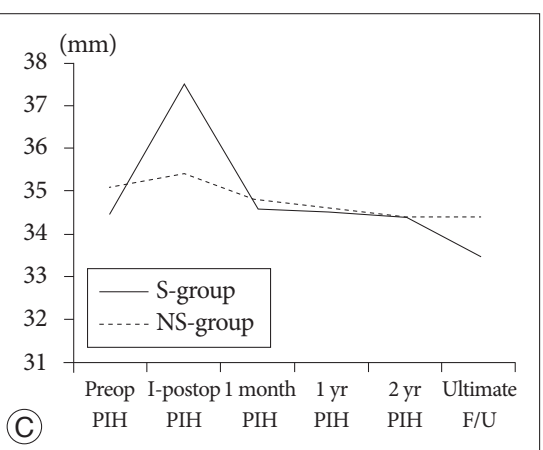

Fig. 2. $A, B$, and $C$ : Preoperative, immediate standing postoperative, 1 month, 1 year, 2 year postoperative, and ultimate follow-up $A l H, M I H$, and PIH (anterior, middle, and posterior intervertebral height) change between S- and NS-group. S : subsidence, NS : non-subsidence, AlH : anterior intervertebral height, MIH : middle intervertebral height, PIH : posterior intervertebral height. 
The demographics and characteristics of both S- and NSgroups are descripted in Table 1 . There was no significant difference in age $(p=0.673)$, gender $(p=0.058)$, level of surgery ( $p=$ $0.357)$ and bone mineral density (BMD) score $(p=0.91)$ between S- and NS-groups.
The fusion rate of ACDF with SAC at the ultimate follow-up was $73.3 \%$ by segmental analysis (96 out of 131 segments), and $70.7 \%$ by population (70 over total 99 patients). There was no statistical significance between fusion rate and subsidence rate $(p=0.158)$, and BMD score $(p=0.058)$.

Table 2. Radiologic and clinical outcomes after ACDF with SAC

\begin{tabular}{|c|c|c|c|}
\hline Postoperative outcomes & Subsidence (S-group) & No subsidence (NS-group) & $p$-value \\
\hline \multicolumn{4}{|l|}{ VAS of neck pain } \\
\hline Preoperative & $5.93 \pm 3.67$ & $6.23 \pm 3.05$ & 0.82 \\
\hline 1 year & $2.58 \pm 2.54$ & $1.35 \pm 1.22$ & 0.80 \\
\hline 2 year & $3.92 \pm 2.73$ & $2.91 \pm 2.70$ & 0.36 \\
\hline Ultimate follow-up & $4.00 \pm 3.21$ & $2.60 \pm 3.41$ & 0.30 \\
\hline \multicolumn{4}{|l|}{ VAS of arm pain } \\
\hline Preoperative & $6.53 \pm 3.16$ & $7.30 \pm 2.36$ & 0.47 \\
\hline 1 year & $2.89 \pm 2.76$ & $2.06 \pm 1.95$ & 0.31 \\
\hline 2 year & $3.29 \pm 2.39$ & $1.91 \pm 2.38$ & 0.17 \\
\hline Ultimate follow-up & $4.57 \pm 3.50$ & $3.20 \pm 3.19$ & 0.33 \\
\hline $\mathrm{TIH}$, anterior $(\mathrm{mm})$ & & & $<0.001$ \\
\hline Immediate postop. & $37.76 \pm 4.05$ & $35.66 \pm 3.23$ & \\
\hline 1 month & $34.58 \pm 3.28$ & $34.78 \pm 3.28$ & \\
\hline 1 year & $33.35 \pm 3.29$ & $34.64 \pm 3.12$ & \\
\hline 2 year & $32.74 \pm 3.44$ & $34.43 \pm 3.09$ & \\
\hline Ultimate follow-up & $32.32 \pm 3.28$ & $34.27 \pm 3.07$ & \\
\hline TIH, middle $(\mathrm{mm})$ & & & $<0.001$ \\
\hline Immediate postop. & $36.52 \pm 3.76$ & $34.19 \pm 3.17$ & \\
\hline 1 month & $33.20 \pm 2.73$ & $33.43 \pm 2.84$ & \\
\hline 1 year & $32.52 \pm 2.90$ & $33.32 \pm 2.96$ & \\
\hline 2 year & $32.20 \pm 2.90$ & $33.24 \pm 3.08$ & \\
\hline Ultimate follow-up & $31.66 \pm 3.04$ & $33.14 \pm 3.07$ & \\
\hline $\mathrm{TIH}$, posterior $(\mathrm{mm})$ & & & $<0.001$ \\
\hline Immediate postop. & $37.47 \pm 3.42$ & $35.38 \pm 3.06$ & \\
\hline 1 month & $34.62 \pm 2.81$ & $34.76 \pm 2.68$ & \\
\hline 1 year & $34.54 \pm 2.85$ & $34.64 \pm 2.98$ & \\
\hline 2 year & $34.36 \pm 2.93$ & $34.41 \pm 3.05$ & \\
\hline Last follow-up & $33.52 \pm 2.85$ & $34.39 \pm 3.07$ & \\
\hline Cage height (mm) & & & 0.85 \\
\hline 5 & $10(14.3 \%)$ & $12(19.7 \%)$ & \\
\hline 6 & $42(60 \%)$ & $36(59 \%)$ & \\
\hline 7 & $13(18.6 \%)$ & $10(16.4 \%)$ & \\
\hline 8 & $4(5.7 \%)$ & $3(4.9 \%)$ & \\
\hline 9 & $1(1.4 \%)$ & 0 & \\
\hline Segmental angle $\left(^{\circ}\right)$ & & & 0.002 \\
\hline Immediate postop. & $-0.75 \pm 5.77$ & $-0.23 \pm 4.99$ & \\
\hline Ultimate follow-up & $4.02 \pm 5.44$ & $0.66 \pm 5.27$ & \\
\hline \multicolumn{4}{|l|}{ Global cervical angle $\left(^{\circ}\right)$} \\
\hline Immediate postop. & $-12.4 \pm 11.8$ & $-12.7 \pm 9.6$ & 0.89 \\
\hline Ultimate follow-up & $-11.9 \pm 11.6$ & $-12.7 \pm 11.2$ & 0.72 \\
\hline \multicolumn{4}{|l|}{ Fusion rate (\%) } \\
\hline Ultimate follow-up & 69.05 & 78.33 & 0.16 \\
\hline \multicolumn{4}{|l|}{ Radiating arm pain (\%) } \\
\hline Ultimate follow-up & 54.3 & 39.3 & 0.01 \\
\hline
\end{tabular}

ACDF : anterior cervical discectomy and inter-body fusion, SAC : stand-alone cages, VAS : visual analog scales, TIH : total intervertebral height 
The kyphotic segmental angle change had statistical significance between S- and NS-group ( $p=0.002)$. From -0.92 degree at the immediate postoperatively to 4.03 degree at the ultimate follow-up was observed which was associated with the higher frequency of AIH subsidence than the MIH or PIH change (Fig. 3). However, the C2-7 global cervical angle had no statistical significance between the two groups ( $p=0.72$ ).

Adjacent segmental disease was occurred in $18(18.2 \%)$ patients. Total $6(6 \%)$ reoperations were performed due to following reasons : acute epidural hematoma formation (one patient), motor weakness aggravation (one patient) and neck or arm pain aggravations as late complications (four patients).

By Odom's criteria, 4 Excellent (1), 31 Good (2), 53 Fair (3), and 11 Poor (4) patients' answers were collected. Total average score of Odom's criteria was 2.71 . And $64.6 \%$ of patients [64 (53

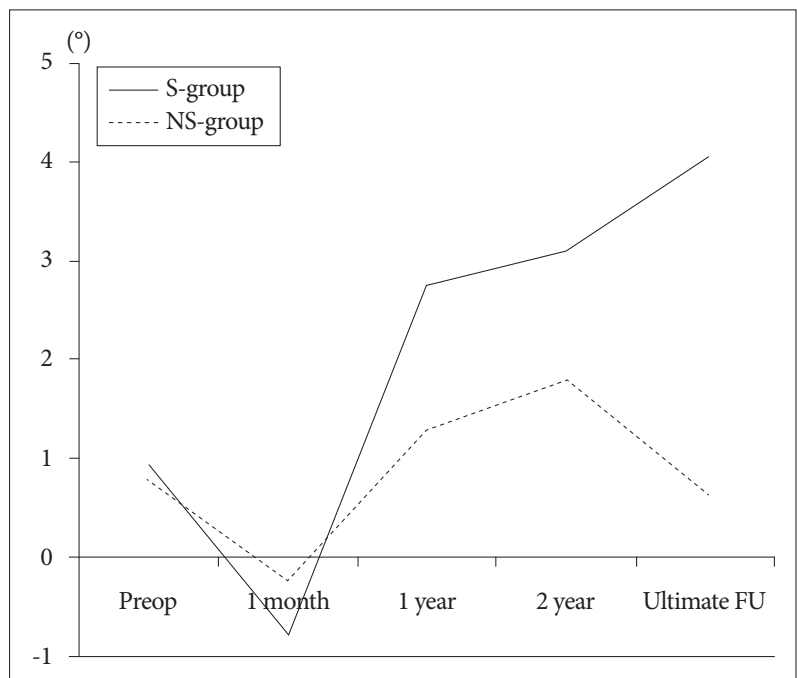

Fig. 3. The preoperative, 1 month, 1 year, and 2 year after surgery, and ultimate follow-up segmental angle change between S- and NS-group. Negative value means lordotic segmental angle. S : subsidence, NS : non-subsidence.

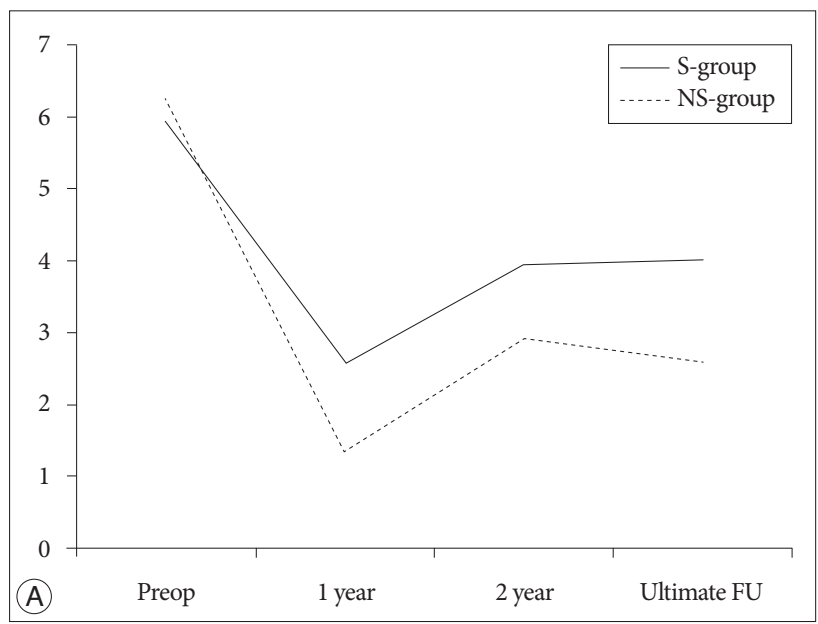

Fair+11 Poor)/99] had unsatisfactory clinical outcome. There was no statistical significance between fusion, subsidence and Odom's criteria ( $p=0.813$ ). The mean score of preoperative neck and arm VAS were 6.89 and 6.07, 2.00 and 2.50 after 1 year the surgery, 3.48 and 2.68 after 2 year the surgery, 4.00 and 3.44 at the ultimate follow-up period (Fig. 4). Compared S- and NSgroup with the neck and arm VAS, neck VAS at the ultimate follow-up period was usually maintained but slightly aggravated than 1 year after surgery, and arm VAS was aggravated over time in the both group (Fig. 5). Subsidence and fusion were not related to the neck or arm VAS ( $p>0.05)$ (Table 3).

\section{DISCUSSION}

This study revealed a radiologic and clinical long-term result with an over average 5-year follow-up data after ACDF with SAC

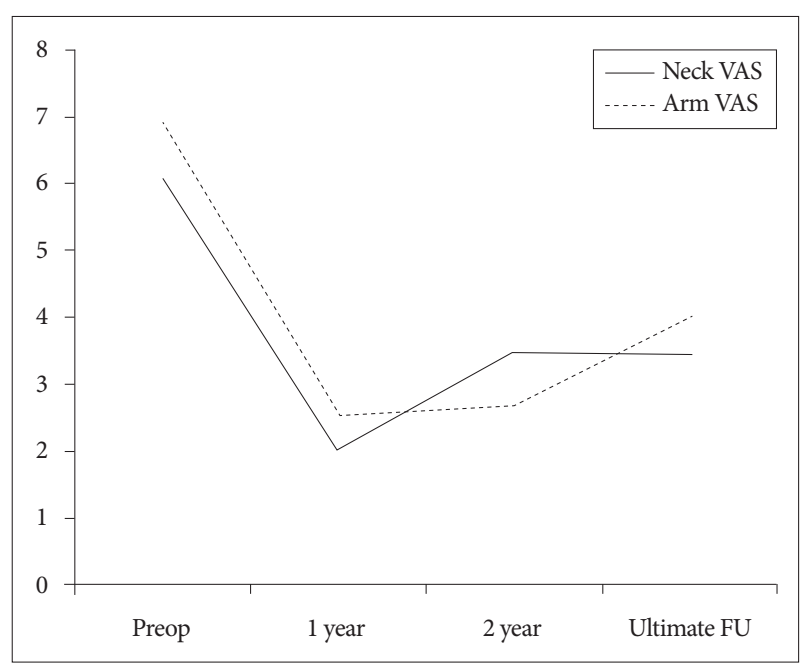

Fig. 5. The preoperative, 1 year, 2 year after surgery, and the ultimate follow-up neck VAS vs. arm VAS change following over time in all ACDF with SAC patients. VAS : visual analog scale, ACDF : Anterior cervical discectomy and inter-body fusion, SAC : stand-alone cages.

Fig. 4. A : The preoperative, 1 year, 2 year after surgery, and the ultimate follow-up neck VAS change between S- and NS-group. B : The preoperative, 1 year, 2 year after surgery, and the ultimate follow-up arm VAS change between S- and NS-group. S : subsidence, NS : non-subsidence, VAS : visual analog scale. 
Table 3. Neck, arm VAS and subsidence, fusion at the ultimate follow-up period

\begin{tabular}{lcccccc}
\hline \multicolumn{1}{c}{ Neck VAS vs. Arm VAS } & S-group & NS-group & $p$-value & F-group & NF-group & $p$-value \\
\hline Ultimate f/u Neck VAS & $4.00 \pm 3.20$ & $2.60 \pm 3.40$ & 0.30 & $3.05 \pm 2.96$ & $4.43 \pm 4.11$ & 0.36 \\
Ultimate f/u Arm VAS & $4.57 \pm 3.50$ & $3.20 \pm 3.19$ & 0.33 & $3.72 \pm 3.32$ & $4.83 \pm 3.71$ & 0.49 \\
\hline
\end{tabular}

S-group : subsidence group, NS-group : non-subsidence group, F-group : fused group, NF-group : non-fused group, f/u : follow-up, VAS : visual analog scale

surgery. Up to date, there had been several reports that investigated about the outcomes of ACDF with SAC. However, most of the results were carried short or intermediate term data below two-year of follow-up, or a few two-year follow-up data with small population. The main stream of the published data about results after ACDF with SAC included subsidence rate as below $30 \%$ to variable and fusion rate higher than $90 \%$ mostly without significant clinical relationship, therefore, the researchers suggested that the outcome of the stand-alone cage procedure was suitable $e^{3,5,9-11,15-18,20,22,23)}$. We previously reported one-year radiologic and clinical outcomes of 3 different construct systems for single-level ACDF using SAC, iliac graft plus plate augmentation, and cage plus plating. In that study, ACDF with SAC represented higher subsidence rate $(58.6 \%)$ and lower fusion rate $(63.2 \%)^{13,14)}$. After following the previous patients in a long-term fashion, it seemed to have inferior results in terms of subsidence and fusion rate according to this study. 74.6\% (53/71) of subsidence occurred within the first 6 month after surgery, the other $25.4 \%$ (18/71) subsidence segments occurred after 6 months. However, the subsidence was progressed over time in the subsidence group even after postoperative one year but was not significantly progressed in the non-subsidence group. Several reports described that the subsidence mostly occurred within one-year after surgery and then be stabled, meaning no more progressed $^{12,13)}$. However in this study, the subsidence was progressed over time slowly. 58.6\% (41/70) of subsided segments were progressed over time continuously until the ultimate follow-up period. Moreover, the fusion rate of $73.3 \%$ meant the nonfused index segments did not achieve bone fusion eventually although a long time past.

The relationships between the demographic data and radiologic/clinical outcome had no statistical significance. This was similar to a previous report ${ }^{1}$. The previous investigator demonstrated that gender, age, level of surgery, cage height and BMD had no significance as outcome factors of the ACDF with SAC surgery ${ }^{1)}$.

Previous researchers suggested that patients having ACDF with SAC experienced pain relief according to the VAS score for two-year follow-up ${ }^{8,11,17,18,20)}$. However, this study demonstrated that the neck and arm VAS score at the ultimate follow-up were increased to compare the score at the two-year follow-up period. Furthermore, the outcome measurement by Odom's criteria, $64.6 \%$ of all patients responded as unsatisfactory (fair to poor). Although the clinical and radiologic outcome had no statistical relationship in this study, overall results of ACDF with SAC had shown to be less satisfactory with the course of time.

This unsatisfactory outcome by Odom's criteria and increased
VAS score meant different manner to previous reports showing ACDF with SAC was suitable. Although we failed to find key factors that affecting the inferior outcomes, it seems that ACDF with SAC surgery did not have superiority to the other ACDF techniques. Therefore, to treat patients of degenerative cervical spine disease, various factors (age, general condition, surgical level, bone quality, segmental/global angle, with or without uncal resection) should be considered thoroughly for optimal care.

The limitations of our study include its retrospective nature, the number of case limitations, the enrolled patients in this study were not randomized meaning biased data and the lack of comparing control group or other ACDF procedure group. The operations were not performed by a single surgeon, and the detailed operation techniques like the extent of endplate preparation or the micro-damage impact to the anterior portion of the cervical vertebral body when the inter-body cages be tapped to be inserted to the intervertebral space were not standardized. Despite a long-term follow-up, the key factors were not identified clearly for the unsatisfactory outcome of ACDF with SAC. Those are also a limitation of this study. In this circumstance, investigations about other factors like, meta-analysis of environmental aspects or patients' specific factors would be helpful for determining the accurate outcome evaluation of ACDF surgery.

\section{CONCLUSION}

Long-term outcomes of ACDF with SAC group were acceptable but not satisfactory. For optimal decision making, more additional comparative long-term outcome data is needed between ACDF with SAC and ACDF with plating.

\section{References}

1. Brenke C, Dostal M, Scharf J, Weiß C, Schmieder K, Barth M : Influence of cervical bone mineral density on cage subsidence in patients following stand-alone anterior cervical discectomy and fusion. Eur Spine J 24 : 2832-2840, 2015

2. Burkhardt JK, Mannion AF, Marbacher S, Kleinstück FS, Jeszenszky D, Porchet F : The influence of cervical plate fixation with either autologous bone or cage insertion on radiographic and patient-rated outcomes after two-level anterior cervical discectomy and fusion. Eur Spine J 24 : $113-119,2015$

3. Cabraja M, Oezdemir S, Koeppen D, Kroppenstedt S : Anterior cervical discectomy and fusion : comparison of titanium and polyetheretherketone cages. BMC Musculoskelet Disord 13 : 172, 2012

4. Cannada LK, Scherping SC, Yoo JU, Jones PK, Emery SE : Pseudoarthrosis of the cervical spine : a comparison of radiographic diagnostic measures. Spine (Phila Pa 1976) 28 : 46-51, 2003

5. Fujibayashi S, Neo M, Nakamura T : Stand-alone interbody cage versus anterior cervical plate for treatment of cervical disc herniation : sequen- 
tial changes in cage subsidence. J Clin Neurosci 15 : 1017-1022, 2008

6. Gercek E, Arlet V, Delisle J, Marchesi D : Subsidence of stand-alone cervical cages in anterior interbody fusion : warning. Eur Spine J 12 : 513516,2003

7. Haden N, Latimer M, Seeley HM, Laing RJ : Loss of inter-vertebral disc height after anterior cervical discectomy. Br J Neurosurg 19 : 469-474, 2005

8. Joo YH, Lee JW, Kwon KY, Rhee JJ, Lee HK : Comparison of fusion with cage alone and plate instrumentation in two-level cervical degenerative disease. J Korean Neurosurg Soc 48 : 342-346, 2010

9. Ji GY, Oh CH, Shin DA, Ha Y, Yi S, Kim KN, et al. : Artificial disk replacement combined with fusion versus 2-level fusion in cervical 2-level disk disease with a 5-year follow-up. J Spinal Disord Tech 2015 [Epub ahead of print]

10. Kao TH, Wu CH, Chou YC, Chen HT, Chen WH, Tsou HK : Risk factors for subsidence in anterior cervical fusion with stand-alone polyetheretherketone (PEEK) cages : a review of 82 cases and 182 levels. Arch Orthop Trauma Surg 134 : 1343-1351, 2014

11. Karikari IO, Jain D, Owens TR, Gottfried O, Hodges TR, Nimjee SM, et al. : Impact of subsidence on clinical outcomes and radiographic fusion rates in anterior cervical discectomy and fusion : a systematic review. J Spinal Disord Tech 27 : 1-10, 2014

12. Kast E, Derakhshani S, Bothmann M, Oberle J : Subsidence after anterior cervical inter-body fusion. A randomized prospective clinical trial. Neurosurg Rev 32 : 207-214; discussion 214, 2009

13. Lee CH, Hyun SJ, Kim MJ, Yeom JS, Kim WH, Kim KJ, et al. : Comparative analysis of 3 different construct systems for single-level anterior cervical discectomy and fusion : stand-alone cage, iliac graft plus plate augmentation, and cage plus plating. J Spinal Disord Tech 26 : 112-118, 2013

14. Lee CH, Kim KJ, Hyun SJ, Yeom JS, Jahng TA, Kim HJ : Subsidence as of 12 months after single-level anterior cervical inter-body fusion. Is it related to clinical outcomes? Acta Neurochir (Wien) 157 : 1063-1068, 2015

15. Marotta N, Landi A, Tarantino R, Mancarella C, Ruggeri A, Delfini R : Five-year outcome of stand-alone fusion using carbon cages in cervical disc arthrosis. Eur Spine J 20 Suppl 1 : S8-S12, 2011

16. Marbacher S, Hidalgo-Staub T, Kienzler J, Wüergler-Hauri C, Landolt
H, Fandino J : Long-term outcome after adjacent two-level anterior cervical discectomy and fusion using stand-alone plasmaphore-covered titanium cages. J Neurol Surg A Cent Eur Neurosurg 76 : 199-204, 2015

17. Pereira EA, Chari A, Hempenstall J, Leach JC, Chandran H, CadouxHudson TA : Anterior cervical discectomy plus intervertebral polyetheretherketone cage fusion over three and four levels without plating is safe and effective long-term. J Clin Neurosci 20 : 1250-1255, 2013

18. Shiban E, Gapon K, Wostrack M, Meyer B, Lehmberg J : Clinical and radiological outcome after anterior cervical discectomy and fusion with stand-alone empty polyetheretherketone (PEEK) cages. Acta Neurochir (Wien) 158:349-355, 2016

19. Smith GW, Robinson RA : The treatment of certain cervical-spine disorders by anterior removal of the intervertebral disc and interbody fusion. J Bone Joint Surg Am 40-A : 607-624, 1958

20. Tabaraee E, Ahn J, Bohl DD, Collins MJ, Massel DH, Aboushaala K, et al. : Comparison of surgical outcomes, narcotics utilization, and costs after an anterior cervical discectomy and fusion : stand-alone cage versus anterior plating. J Spinal Disord Tech 2015 [Epub ahead of print]

21. van Jonbergen HP, Spruit M, Anderson PG, Pavlov PW : Anterior cervical interbody fusion with a titanium box cage : early radiological assessment of fusion and subsidence. Spine J 5 : 645-649; discussion 649, 2005

22. Yamagata T, Takami T, Uda T, Ikeda H, Nagata T, Sakamoto S, et al. : Outcomes of contemporary use of rectangular titanium stand-alone cages in anterior cervical discectomy and fusion : cage subsidence and cervical alignment. J Clin Neurosci 19: 1673-1678, 2012

23. Yoo M, Kim WH, Hyun SJ, Kim KJ, Jahng TA, Kim HJ : Comparison between two different cervical interbody fusion cages in one level standalone $\mathrm{ACDF}$ : carbon fiber composite frame cage versus polyetheretherketone cage. Korean J Spine 11 : 127-135, 2014

24. Yue WM, Brodner W, Highland TR : Long-term results after anterior cervical discectomy and fusion with allograft and plating : a 5- to 11-year radiologic and clinical follow-up study. Spine (Phila Pa 1976) 30 : 21382144, 2005

25. Zoëga B, Kärrholm J, Lind B : Outcome scores in degenerative cervical disc surgery. Eur Spine J 9: 137-143, 2000 